Tropical Journal of Pharmaceutical Research September 2021; 20 (9): 1801-1809

ISSN: $1596-5996$ (print); 1596-9827 (electronic)

(C) Pharmacotherapy Group, Faculty of Pharmacy, University of Benin, Benin City, 300001 Nigeria.

Original Research Article

http://dx.doi.org/10.4314/tjpr.v20i9.4

\title{
Dietary treatment with omega fatty acids mediates in vitro rumen fermentation kinetics and reduce methane emission in water buffalo
}

\author{
Mengwei Li'1a, Faiz-ul Hassan ${ }^{1,2 a}$, Lijuan Peng ${ }^{1}$, Hossam Mahrous Ebeid ${ }^{3}$, \\ Zhenhua Tang ${ }^{1}$, Fang Xie ${ }^{1}$, Kaiping Peng ${ }^{1}$ and Chengjian Yang ${ }^{1 *}$ \\ ${ }^{1}$ Key Laboratory of Buffalo Genetics, Breeding and Reproduction Technology, Ministry of Agriculture and Guangxi Buffalo \\ Research Institute, Chinese Academy of Agricultural Sciences, Nanning 530001, China, 'Institute of Animal and Dairy \\ Sciences, Faculty of Animal Husbandry, University of Agriculture, Faisalabad-38040, Pakistan, ${ }^{3}$ Dairy Science Department, \\ National Research Centre, 33 Bohouth St. Dokki, Giza 12311, Egypt
}

*For correspondence: Email: ycj0746@sina.com

Sent for review: 17 January 2021

Revised accepted: 30 August 2021

\begin{abstract}
Purpose: To investigate the effect of dietary supplementation of two omega fatty acids on in vitro rumen fermentation, microbial populations, total gas and methane $\left(\mathrm{CH}_{4}\right)$ production.

Methods: Both linoleic and linolenic acids were supplemented at 0 (control), 1, 3, 5 and $7 \%$ of dry matter (DM) in a ration with a high roughage to concentrate ratio (70: 30). Total gas and $\mathrm{CH} 4$ were measured at 3, 6, 9, 12 and $24 \mathrm{~h}$ of fermentation while $\mathrm{pH}$, volatile fatty acids (VFA), and ammonia nitrogen $\left(\mathrm{NH}_{3}-\mathrm{N}\right)$ concentrations were measured at $24 \mathrm{~h}$ using buffalo rumen fluid in an in vitro batch culture system. Microbial populations were determined using 16S-rDNA gene primers by RT-PCR.

Results: The results revealed that linoleic acid at 3, 5 and $7 \%$ decreased the concentration of $\mathrm{NH}_{3}-\mathrm{N}(\mathrm{p}$ $<0.05)$ but linolenic acid at 5 and $7 \%$ increased $N_{3}-N(p<0.05)$. A linear decrease $(p<0.001)$ in acetate and butyrate, coupled with linear increase $(p<0.001)$ in propionate was observed in response to treatment. Furthermore, supplementation of 3, 5 and $7 \%$ of both fatty acids linearly $(p<0.001)$ decreased total gas and $\mathrm{CH}_{4}$ production when compared to the control. The addition of linoleic acid linearly $(p<0.001)$ decreased the number of protozoa without affecting methanogens, while linolenic acid linearly and quadratically $(p<0.001)$ reduced the population of both protozoa and methanogens $(p$ $<0.05)$.

Conclusion: Linolenic acid is more effective at a $3 \%$ level in reducing methane production (up to $63 \%$ ) in high roughage diets.
\end{abstract}

Keywords: Linoleic acid, Linolenic acid, Rumen fermentation, Methane emission

This is an Open Access article that uses a funding model which does not charge readers or their institutions for access and distributed under the terms of the Creative Commons Attribution License (http://creativecommons.org/licenses/by/4.0) and the Budapest Open Access Initiative (http://www.budapestopenaccessinitiative.org/read), which permit unrestricted use, distribution, and reproduction in any medium, provided the original work is properly credited.

Tropical Journal of Pharmaceutical Research is indexed by Science Citation Index (SciSearch), Scopus, International Pharmaceutical Abstract, Chemical Abstracts, Embase, Index Copernicus, EBSCO, African Index Medicus, JournalSeek, Journal Citation Reports/Science Edition, Directory of Open Access Journals (DOAJ), African Journal Online, Bioline International, Open-J-Gate and Pharmacy Abstracts

\section{INTRODUCTION}

Ruminants are vital for human life because they provide nutritious food products (milk and meat) by utilizing tons of crop byproducts and agricultural wastes. Nature has bestowed ruminants with a robust consortium of microbes that degrade highly cellulosic fibrous feedstuffs in the rumen to provide energy and essential nutrients to the host. During rumen fermentation, 
ammonia $\left(\mathrm{NH}_{3}\right)$ and methane $\left(\mathrm{CH}_{4}\right)$ are produced along with other volatile fatty acids. Ruminants contribute about $44 \%$ of enteric methane to total global greenhouse gas emissions (GHG) from the livestock sector [1]. Highly fibrous feeds like roughages yield higher quantities of $\mathrm{CH}_{4}$ per unit of dry matter compared with low fiber (starch-rich) diets [2]. Greenhouse gases are considered a major cause of depletion of the ozone layer and resulting in climate changes and global warming issues. Therefore, scientists are continuously striving to develop strategies to reduce enteric methane production in ruminants to reduce overall GHG emissions from livestock. Many interventions have been used to achieve this essential hard task mainly through dietary manipulation, including altering roughage to concentrate ratios and supplementation of different feed additives [3].

The primary target regarding methane mitigation strategies is to manipulate rumen biohydrogenation by shifting microbial populations to reduce $\mathrm{H}_{2}$ yield that is the ultimate source of enteric methane production. Dietary supplementation with vegetable oils and fatty acids has been conceived as a promising strategy to reduce methane emanation from livestock owing to their potential to shift rumen biohydrogenation and toxic effects on protozoa and methanogens. Vegetable oils (like rapeseed, sunflower, linseed, and moringa) rich in unsaturated fatty acids (C-18 fatty acids), have shown to shift rumen fermentation kinetics leading to reduced methanogenesis [4]. However, quantity and fatty acids composition of dietary fat determine the extent of inhibitory effect on rumen biohydrogenation and methanogenesis [5].

The unsaturated fatty acids (UFA) in diet act as alternative hydrogen sink and modulate rumen fermentation kinetics by decreasing acetate to propionate ratio and $\mathrm{CH} 4$ production $[2,6]$. Studies have shown that fat supplements containing different long-chain fatty acids with different degrees of unsaturation revealing variable effects regarding acetate and propionate production in the rumen [7]. Compound C-18 fatty acids with an increasing degree of unsaturation decreased overall VFAs, including acetate and butyrate during in vitro fermentation
[8]. The addition of long-chain unsaturated fatty acids has revealed an increase in rumen bacterial contents and dehydrogenase activity but decreased protozoa. Moreover, it has also affected the concentration of VFAs produced during in vitro fermentation in goats [9].

Studies involving dietary supplementation of fatty acids showed that the effect of different fatty acids on rumen fermentation is variable and perhaps related to the degree of unsaturation and level of supplementation of individual fatty acids in different diets $[8,9]$. Understanding of possible effects of individual unsaturated fatty acids on rumen fermentation, microbial population, and their subsequent effects on methanogens is required to show their potential as feed additives to mitigate methane emanation. No information regarding the effect of C-18 unsaturated fatty acids (especially linoleic and linolenic acid) on rumen fermentation kinetics and methanogenesis is present in buffaloes. Therefore, this study aimed to provide insights into the potential effects of supplementation of linoleic and linolenic acid on in vitro fermentation kinetics and methanogenesis of a high roughage diet.

\section{EXPERIMENTAL}

\section{Experimental diet and treatments}

The experimental diet (substrate) consisted of elephant grass as a roughage and commercial corn-based concentrate mixture. The chemical composition of the substrate was determined with proximate analysis and presented in Table 1. Weighed quantity of elephant grass $(0.35 \mathrm{~g})$ and concentrate $(0.15 \mathrm{~g})$ was used to make an in vitro fermentation substrate consisting of roughage to concentrate ratio of 70:30. Linoleic and linolenic acid (C-18 fatty acids) were purchased from Sigma Aldrich (Cat no. L1376 and L2376, respectively). Both acids were supplemented at $1,3,5$, and $7 \%$ of dry matter of the substrate individually. A blank group (without additives and substrates) and a control group (without additives) were used for each treatment group.

Table 1: Chemical composition of the substrates (air-dry basis)

\begin{tabular}{lcccc}
\hline Substrate & CP $(\%)$ & Energy (cal/g) & ADF (\%) & NDF (\%) \\
\hline Elephant grass & 6.33 & 4164.07 & 55.1 & 91.01 \\
Concentrate & 16.3 & 3956.21 & 13.34 & 62.87 \\
\hline
\end{tabular}

CP: Crude protein, ADF: Acid detergent fiber, NDF: Neutral detergent fiber 


\section{Collection of rumen fluid for inoculum}

Three crossbred (Murrah $\times$ Chinese local) water buffaloes were used to collect rumen inoculum. These buffaloes had permanent rumen canula fitted and weighed $600 \pm 50 \mathrm{~kg}$. These buffaloes were fed on grass and concentrate two times a day (8:00 am and 3:00 pm), with free access to drinking water. Rumen fluids were collected from top, middle and bottom of the rumen in a thermos bottle before morning feeding at 8:00 am, and quickly transferred to the laboratory. The collected sample were squeezed into Schott Duran bottle (Schott North America Inc, Elmsford, NY) with four layered cheesecloth under continuous $\mathrm{CO}_{2}$ flushing. This process was performed in a water bath at $39{ }^{\circ} \mathrm{C}$. The squeezed rumen liquor samples were then mixed in equal proportion before inoculation. The animal study was approved by the institutional ethical committee and followed internal guidelines for animal studies.

\section{In vitro rumen fermentation}

In this experiment, in vitro fermentation flasks were used for a continuous batch culture system. For the process of in vitro fermentation, buffer solution (40 mL) was taken in the flasks and kept for $24 \mathrm{~h}$ at $39{ }^{\circ} \mathrm{C}$ in the incubator. The mixed inoculation mixture $(10 \mathrm{~mL})$ free of feed particles was added into each in vitro fermentation flasks. The total volume of the in vitro batch culture system was $50 \mathrm{~mL}$. Substrate $(0.5 \mathrm{~g})$ was added to $180 \mathrm{~mL}$ fermentation flasks with the respective addition of fatty acids on a DM basis. Both acids were supplemented individually at $1,3,5$, and 7 $\%$ of the substrate (on dry matter basis). Then all flasks were flushed with $\mathrm{CO}_{2}$ and rubber stopper was inserted to close it tightly. The flasks were sealed with aluminium caps and put into incubator for $48 \mathrm{~h}$ at $39^{\circ} \mathrm{C}$. Second run of the experiment with same conditions was repeated next week. For every treatment three fermentation flasks $(3 \times 5)$ and three flasks containing only rumen fluid were incubated.

\section{Determination of fermentation parameters}

To stop the fermentation process after $48 \mathrm{~h}$ of incubation, the flasks were swirled into the ice. A portable $\mathrm{pH}$ meter (HANNA HI 8424, USA) was used to measure the $\mathrm{pH}$ of samples. For the measurement of ammonia- $\mathrm{N}$ ( $\left.\mathrm{NH}_{3}-\mathrm{N}\right)$ concentration, indophenol method was used. Spectrophotometer at a wavelength of $595 \mathrm{~nm}$ was used to analyse microbial crude protein (MCP) using bovine serum albumin solution 1 $\mathrm{mg} / \mathrm{mL}$ (Sigma-Aldrich Co., LLC, St. Louis, Missouri, USA) as a standard equivalent. The
VFA contents were measured with GC system (Agilent 7890A), using crotonic acid as an internal standard and HP-INNOWAX (19091N133) capillary column $(30 \mathrm{~m} \times 0.25 \mathrm{~mm} \times 0.25$ $\mu \mathrm{m})$ with an inlet temperature of $200{ }^{\circ} \mathrm{C}$. VFA fractions $\left(\mathrm{C}_{2}, \mathrm{C}_{3}, \mathrm{C}_{4}, \mathrm{C}_{5}, \mathrm{iC}_{4}\right.$, and $\left.\mathrm{iC}_{5}\right)$ for each treatment were determined.

\section{Total gas and methane production}

Total gas production volume $(\mathrm{mL})$ from each culture flask was measured using a glass syringe 3, 6, 9, 12 and $24 \mathrm{~h}$. Similarly for each time interval. Gas chromatography (GC) system (7890A, Agilent Technologies, USA) was used for the measurement of $\mathrm{CH}_{4}$ concentration. The film thickness of capillary column was $30 \mathrm{~m} \times$ $0.32 \mathrm{~mm} \times 0.25 \mathrm{~mm}$ (GC-14B, Shimadzu, USA). A gas-tight syringe was used to take $10 \mu \mathrm{L}$ gas sample from each flask during each incubation period and then sample was injected into $\mathrm{GC}$ system manually for the determination of $\mathrm{CH}_{4}$ concentration. Isothermal oven temperature was maintained at $50{ }^{\circ} \mathrm{C}$ with a retention time of 1.2 min. Total $\mathrm{CH}_{4}$ production was calculated by plotting calibration curves using five different $\mathrm{CH}_{4}$ gas standards.

\section{DNA extraction and determination of microbial populations}

The CTAB method was used to extract DNA from pelleted microbial mass samples, as reported by Yu and Morrison [10]. The DNA quality was assessed with Nanodrop. For the quantification of total bacteria, anaerobic fungi, methanogens and protozoa populations, quantitative real-time polymerase chain reaction (qRT-PCR) was performed. For this, Roche light cycler 480 RTPCR machine (Roche, Basel, Switzerland) was used. For determining the quantity of bacteria, anaerobic fungi and methanogens previously designed 16S-rRNA primer pairs were utilized, while for determining the quantity of protozoa 18S-rRNA primers were utilized as listed in Table 2. Total PCR reaction volume was $20 \mu \mathrm{L}$ having nuclease-free water $(8.0 \mu \mathrm{L})$, SYBR green mixture $(9.2 \mu \mathrm{L})$ and each of forward and reverse primers $(1 \mu \mathrm{L})$ of particular species $(10 \mu \mathrm{M})$. The amplification profile of RT-PCR for all primer pairs consisted of an initial denaturation for 10 min, followed by 40 cycles of $95^{\circ} \mathrm{C}$ for $15 \mathrm{~s}$ and annealing at $60^{\circ} \mathrm{C}$ for $60 \mathrm{~s}$. Extracted DNA from microbial cultures was diluted to ten folds for plotting standard curves after amplification through conventional PCR $\left(95^{\circ} \mathrm{C}\right.$ for $10 \mathrm{~s}, 60{ }^{\circ} \mathrm{C}$ for $60 \mathrm{~s}$ for 40 cycles). Spectrophotometer (Nanodrop2000) was utilized for measuring the concentration of PCR products. The copy number of each standard was calculated using 
the length of the PCR products length and its respective concentration of DNA was used for calculation of copy number for each standard. The threshold cycle (CT) values for standard curves were used to calculate the copy number of each unknown samples.

\section{Statistical analysis}

The data thus collected were analyzed using the general linear model in SPSS 19.0 software, and Duncan's multiple range test was performed for multiple comparisons between groups. Statistical significance was considered at $p<0.05$.

\section{RESULTS}

Effect of omega fatty acid supplementation on in vitro rumen fermentation parameters

The supplementation of linoleic and linolenic acid significantly $(p<0.05)$ affected the $\mathrm{pH}$ and $\mathrm{NH}_{3}-$ $\mathrm{N}$ concentration of in vitro rumen fermentation (Table 3). Compared with the control group, supplementation of 1 and $7 \%$ linoleic acid increased the $\mathrm{pH}(p=0.001)$, while linolenic acid at 3,5 and $7 \%$ linearly $(p=0.006)$ and quadratically $(p=0.009)$ increased the $\mathrm{pH}$ of the rumen fluid $(p<0.05)$. Moreover, the addition of the linoleic acid (at 3,5 , and $7 \%$ ) linearly ( $p=$ $0.031)$ and quadratically $(p=0.008)$ reduced the $\mathrm{NH}_{3}-\mathrm{N}$ concentration, while linolenic acid (at 5 and $7 \%$ ) increased $(p<0.05)$ the $\mathrm{NH}_{3}-\mathrm{N}$ concentration linearly and quadratically in the in vitro fermentation.

Results revealed that different levels of linoleic and linolenic acid significantly affected the VFA concentration (Table 3 ). The supplementation of linoleic acid above $3 \%$ resulted in a linear decrease in concentrations of acetic, butyric, and isobutyric acid $(p=0.001)$, while the concentration of propionic acid linearly increased
$(P=0.001)$. However, $5 \%$ of linoleic acid decreased $(p<0.05)$ the concentration of valeric acid. Similarly, supplementation of linolenic acid also linearly reduced $(p=0.001)$ the concentrations of acetic and butyric acid. The concentration of propionic acid was linearly increased with the addition of linolenic acid above $1 \%(p=0.001)$ level but it had no effect on the concentration of valeric acid ( $p>0.05$ ). Supplementation of linoleic acid above $3 \%$ showed a linear decrease $(p=0.001)$ in the acetate: propionate ratio compared with the control group. However, linolenic acid decreased this ratio linearly and quadratically $(P=0.001)$ at all levels when compared to the control group but the effect of 3,5 and $7 \%$ supplementation was not different amongst each other. Linoleic acid had no effect on the yield of total VFAs but linolenic acid significantly decreased total VFA at all levels when compared to the control. However, comparison of higher levels (5 and $7 \%$ ) of linolenic acid revealed no effect on total VFAs.

\section{Effect of omega fatty acid supplementation on total gas and methane production}

Supplementation with linoleic acid at $\geq 3 \%$ linearly reduced $(p=0.001)$ the total gas and $\mathrm{CH}_{4}$ production (Table 4). Similarly, linolenic acid above $3 \%$ linearly reduced $(P=0.001)$ the gas production and $\mathrm{CH}_{4}$ production $(p<0.001)$. A highest reduction of 35 and $44 \%$ was observed in total gas production response to supplementation of linoleic and linolenic acids, respectively. Highest reduction in total $\mathrm{CH}_{4}$ production up to 96 and $97 \%$ was observed with $7 \%$ of linoleic and linolenic acids, respectively. The trend of gas kinetics at 3, 6, 9, 12 and $24 \mathrm{~h}$ of incubation in response to treatment is shown in Figure 1 and Figure 2. The effect of linolenic and linoleic acids on $\mathrm{CH}_{4}$ production at different time intervals is presented in Figure 3 and Figure 4 , respectively.

Table 2: Primers used for qRT-PCR

\begin{tabular}{|c|c|c|c|}
\hline Target strain & Primer & Primer sequence & $\begin{array}{l}\text { Product } \\
\text { length } \\
\text { (bp) }\end{array}$ \\
\hline \multirow[t]{2}{*}{ Total Bacteria } & $\mathrm{F}$ & CGGCAACGACCGCAACCC & 130 \\
\hline & $\mathrm{R}$ & CCATTGTAGCACGTGTGTAGCC & \\
\hline \multirow[t]{2}{*}{ Total Fungi } & $\mathrm{F}$ & GAGGAAGTAAAAGTCGTAACAAGGTTTC & 120 \\
\hline & $\mathrm{R}$ & CAAATTCACAAAGGGTAGGATGATT & \\
\hline \multirow[t]{2}{*}{ Total Protozoa } & $\mathrm{F}$ & GCTTTCGWTGGTAGTGTATT & 223 \\
\hline & $\mathrm{R}$ & CTTGCCCTCYAATCGTWCT & \\
\hline \multirow{2}{*}{$\begin{array}{l}\text { Total } \\
\text { Methanogens }\end{array}$} & $\mathrm{F}$ & TTCGGTGGATCDCARAGRGC & 140 \\
\hline & $\mathrm{R}$ & GBARGTCGWAWCCGTAGAATCC & \\
\hline
\end{tabular}

Note: $\mathrm{F}=$ forward; $\mathrm{R}=$ reverse 
Table 3: Effect of omega acids on in vitro rumen fermentation parameters

\begin{tabular}{|c|c|c|c|c|c|c|c|c|c|c|}
\hline \multirow{2}{*}{ Parameter } & \multirow{2}{*}{ Treatment } & \multicolumn{5}{|c|}{ Amount of the additive (substrate dry matter) } & \multirow{2}{*}{ SEM } & \multicolumn{3}{|c|}{$P$-value } \\
\hline & & 0 & $1 \%$ & $3 \%$ & $5 \%$ & $7 \%$ & & Treat. & Linear & Quad. \\
\hline \multirow{2}{*}{$\mathrm{pH}$} & Linoleic acid & $6.66^{c}$ & $6.83^{a}$ & $6.72^{\mathrm{bc}}$ & $6.72^{\mathrm{bc}}$ & $6.78^{\mathrm{ab}}$ & 0.024 & 0.001 & 0.097 & 0.244 \\
\hline & Linolenic acid & $6.62^{c}$ & $6.66^{b c}$ & $6.68^{\mathrm{ab}}$ & $6.71^{\mathrm{a}}$ & $6.66^{b c}$ & 0.014 & 0.006 & 0.006 & 0.009 \\
\hline \multirow{4}{*}{$\begin{array}{l}\text { Acetic acid } \\
\text { (mmol/L) } \\
\text { Propionic acid } \\
\text { (mmol/L) }\end{array}$} & Linoleic acid & $9.28^{a}$ & $9.36^{a}$ & $8.56^{b}$ & $8.51^{b}$ & $8.13^{b}$ & 0.206 & 0.001 & 0.001 & 0.85 \\
\hline & Linolenic acid & $8.99^{a}$ & $7.81^{b}$ & $6.31^{c}$ & $5.84^{c}$ & $5.97^{c}$ & 0.19 & 0.001 & 0.001 & 0.001 \\
\hline & Linoleic acid & $5.15^{c}$ & $5.52^{c}$ & $6.24^{b}$ & $7.64^{a}$ & $7.70^{\mathrm{a}}$ & 0.214 & 0.001 & 0.001 & 0.95 \\
\hline & Linolenic acid & $5.60^{\mathrm{b}}$ & $5.44^{b}$ & $7.08^{a}$ & $6.77^{a}$ & $6.80^{a}$ & 0.27 & 0.001 & 0.001 & 0.14 \\
\hline \multirow{2}{*}{ Butyric acid } & Linoleic acid & $3.93^{a}$ & $3.56^{\mathrm{ab}}$ & $3.19^{b}$ & $2.53^{c}$ & $2.42^{\mathrm{c}}$ & 0.152 & 0.001 & 0.001 & 0.71 \\
\hline & Linolenic acid & $3.52^{\mathrm{a}}$ & $2.75^{b}$ & $2.07^{c}$ & $1.63^{\mathrm{cd}}$ & $1.23^{d}$ & 0.181 & 0.001 & 0.001 & 0.17 \\
\hline \multirow{2}{*}{ Valeric acid } & Linoleic acid & $0.17^{a}$ & $0.18^{a}$ & $0.16^{a}$ & $0.11^{\mathrm{b}}$ & $0.16^{a}$ & 0.011 & 0.01 & 0.054 & 0.23 \\
\hline & Linolenic acid & 0.134 & 0.156 & 0.116 & 0.137 & 0.149 & 0.011 & 0.18 & 0.75 & 0.36 \\
\hline \multirow{2}{*}{$\begin{array}{l}\text { Acetic acid / } \\
\text { Propionic acid }\end{array}$} & Linoleic acid & $1.81^{\mathrm{a}}$ & $1.71^{\mathrm{a}}$ & $1.38^{\mathrm{b}}$ & $1.11^{\mathrm{c}}$ & $1.06^{c}$ & 0.066 & 0.001 & 0.001 & 0.55 \\
\hline & Linolenic acid & $1.61^{a}$ & $1.44^{\mathrm{b}}$ & $0.89^{c}$ & $0.87^{c}$ & $0.88^{c}$ & 0.039 & 0.001 & 0.001 & 0.001 \\
\hline \multirow{2}{*}{ Total VFAs } & Linoleic acid & 18.8 & 18.89 & 18.35 & 19.0 & 18.6 & 0.352 & 0.71 & 0.8 & 0.88 \\
\hline & Linolenic acid & $18.25^{a}$ & $16.17^{b}$ & $15.58^{b c}$ & $14.39^{c}$ & $14.16^{c}$ & 0.458 & 0.001 & 0.001 & 0.09 \\
\hline \multirow{4}{*}{$\begin{array}{l}\text { Ammonia-N } \\
(\mathrm{mg} / 100 \mathrm{~mL}) \\
\text { Microbial Protein } \\
(\mathrm{mg} / \mathrm{mL})\end{array}$} & Linoleic acid & $15.90^{\mathrm{a}}$ & $15.19^{a b}$ & $12.61^{\mathrm{c}}$ & $12.63^{c}$ & $13.26^{b c}$ & 0.757 & 0.031 & 0.008 & 0.097 \\
\hline & Linolenic acid & $9.47^{b}$ & $9.66^{a b}$ & $9.22^{\mathrm{b}}$ & $11.18^{a}$ & $11.03^{a}$ & 0.488 & 0.031 & 0.009 & 0.359 \\
\hline & Linoleic acid & $12.61^{b}$ & $13.58^{b}$ & $15.17^{a}$ & $15.29^{a}$ & $13.89^{a b}$ & 0.495 & 0.008 & 0.016 & 0.004 \\
\hline & Linolenic acid & $16.31^{a}$ & $18.09^{a}$ & $16.32^{\mathrm{a}}$ & $13.67^{\mathrm{b}}$ & $14.19^{b}$ & 0.565 & 0.001 & 0.001 & 0.13 \\
\hline
\end{tabular}

Table 4: Effect of omega acids on total gas and methane production

\begin{tabular}{|c|c|c|c|c|c|c|c|c|c|c|}
\hline \multirow{2}{*}{ Item } & \multirow{2}{*}{ Fatty acid } & \multicolumn{5}{|c|}{ Amount of the additive (on dry matter basis) } & \multirow{2}{*}{ SEM } & \multicolumn{3}{|c|}{$P$-value } \\
\hline & & $0 \%$ & $1 \%$ & $3 \%$ & $5 \%$ & $7 \%$ & & Treat. & Linear & Quad. \\
\hline Gas production & Linoleic acid & $181.7^{a}$ & $184.2^{\mathrm{a}}$ & $161.2^{b}$ & $133.7^{c}$ & $127.7^{c}$ & 4.19 & 0.001 & 0.001 & 0.19 \\
\hline$(\mathrm{ml} / \mathrm{g} \mathrm{DM})$ & Linolenic acid & $186.2^{\mathrm{a}}$ & $180.7^{a}$ & $148.2^{b}$ & $116.7^{c}$ & $104.2^{\mathrm{c}}$ & 5.52 & 0.001 & 0.001 & 0.54 \\
\hline $\mathrm{CH}_{4}$ production & Linoleic acid & $92.01^{a}$ & $90.95^{a}$ & $69.45^{b}$ & $46.65^{c}$ & $38.80^{c}$ & 3.71 & 0.001 & 0.001 & 0.28 \\
\hline$(\mathrm{ml} / \mathrm{g} \mathrm{DM})$ & Linolenic acid & $85.78^{a}$ & $82.45^{a}$ & $33.79^{b}$ & $14.69^{c}$ & $1.36^{\mathrm{d}}$ & 2.63 & 0.001 & 0.001 & 0.35 \\
\hline
\end{tabular}

$\mathrm{CH}_{4}=$ Methane, DM = Dry matter

Table 5: Effect of omega acids on rumen microbial populations ( $\log _{10}$ copies per $\mathrm{g}$ )

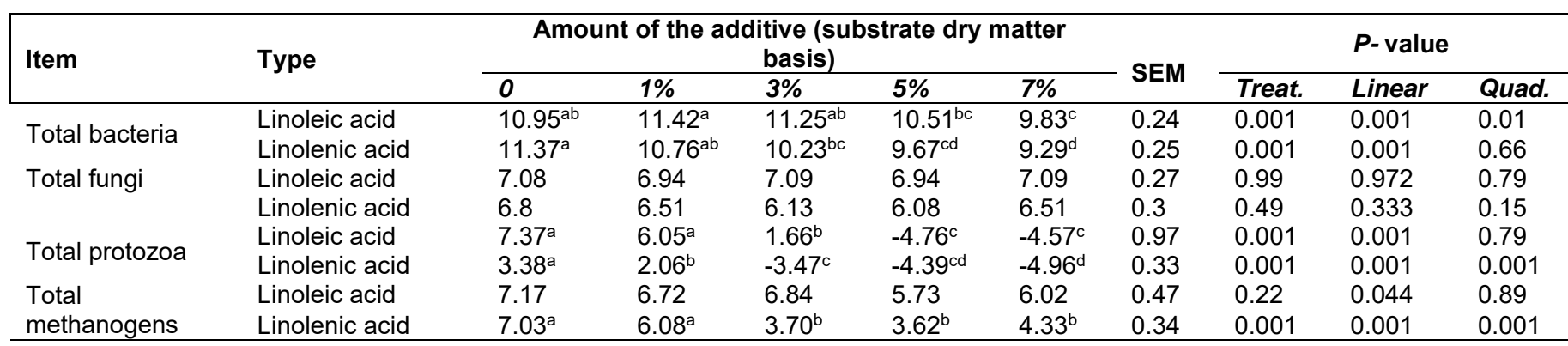

Effects of omega fatty acid supplementation on rumen microbial populations

The supplementation of linoleic acid at levels $\geq$ $5 \%$ resulted in a linear decrease $(p=0.001)$ in the population of total bacteria, but below this level, it showed a positive effect on bacterial populations (Table 5). However, linoleic acid had no effects on total methanogens $(p>0.05)$. Supplementation of both fatty acids produced no significant effect on the total fungal contents $(P>$ $0.05)$. Linoleic acid linearly reduced $(p=0.001)$ the numer of protozoa at $\geq 5 \%$, but linolenic linearly and quadratically reduced $(p=0.001)$ the number of protozoa at all level, exhibiting highly toxic effects on protozoa. Linolenic acid showed pronounced effects on total bacteria as supplementation above $1 \%$ linearly $(p=0.001)$ reduced the total bacterial counts when compared to the control. Similarly, linoleic acid also exhibited toxic effects on total methanogens as it linearly and quadratically reduced the total methanogens at $\geq 3 \%$ level of supplementation $(p=0.001)$.

\section{DISCUSSION}

Rumen $\mathrm{pH}$ is an important parameter used as a marker of rumen homeostasis. It is generally affected by the amount of saliva secreted, accumulation of organic acids, and nature of the diet. Abrupt fluctuations in $\mathrm{pH}$ (too high or too low) adversely affect the growth of rumen microbes and fermentation process 8 . 


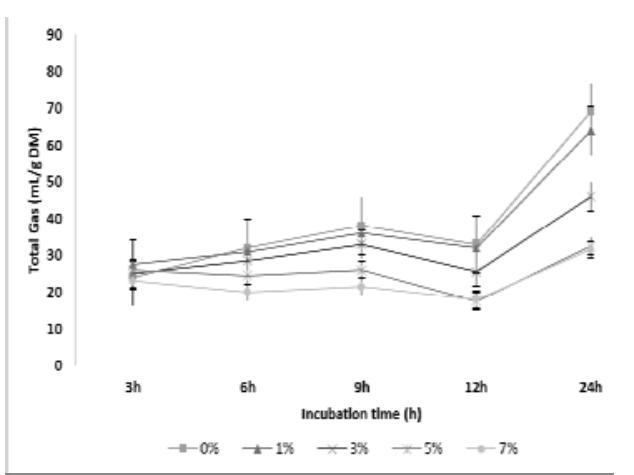

Figure 1: Effect of linolenic acid on total gas production at different time intervals

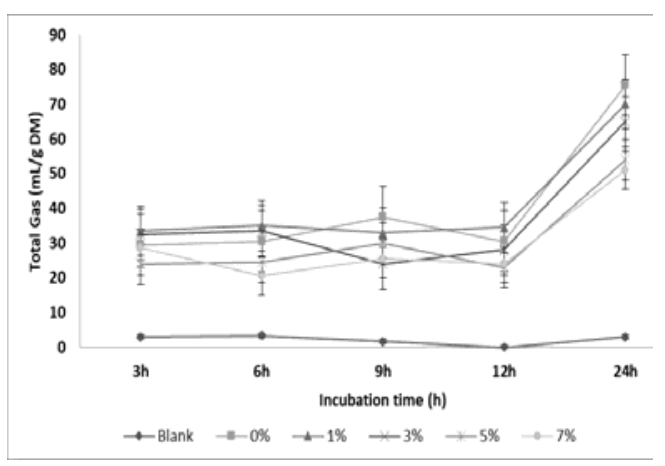

Figure 2: Effect of linoleic acid on total gas production at different time intervals

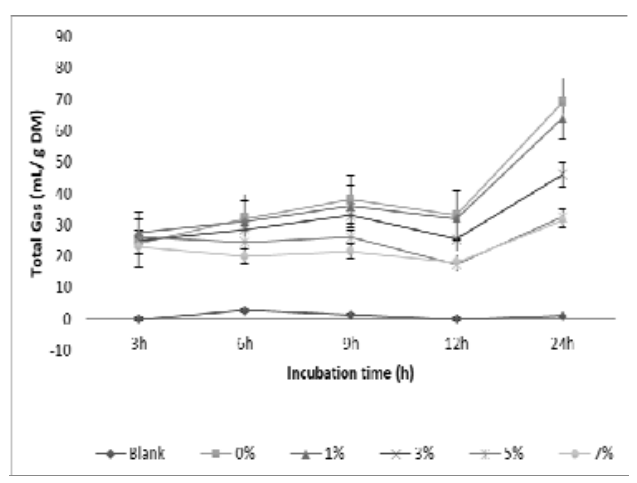

Figure 3: Effect of linolenic acid on methane production at different time intervals

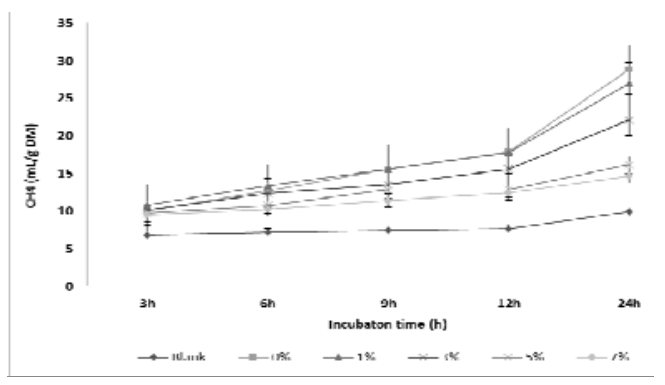

Figure 4: Effect of linoleic acid on methane production at different time intervals
The optimal $\mathrm{pH}$ values for protozoa, anaerobic fungi, and bacterial growth are 5.8, 7.5, and $6.0-$ 7.0 , respectively. The normal rumen $\mathrm{pH}$ range is 6.0 - 7.0, which is suitable for digestion and absorption of rumen nutrients. Studies have shown that the rumen environment can adapt to different concentrations of dietary fatty acids without being affected [11]. In this study, the $\mathrm{pH}$ of rumen fluid during in vitro fermentation was between 6.6 and 6.9, which was within the normal range.

The concentration of $\mathrm{NH}_{3}-\mathrm{N}$ in the rumen is related to protein degradation rate, energy and nitrogen balance, and efficiency of N-utilization by microbes during fermentation. Appropriate $\mathrm{NH}_{3}-\mathrm{N}$ concentration is required for the adaptation of rumen microbes to ensure proper microbial growth and efficiency of MCP synthesis. Higher $\mathrm{NH}_{3}-\mathrm{N}$ concentrations indicate that the rate of ammonia utilization by microorganisms is not consistent with the rate of ammonia production, which might cause protein wastage. In this study, the addition of linoleic acid significantly reduced while linolenic acid increased $\mathrm{NH}_{3}-\mathrm{N}$ concentration, revealing that both have different effects on buffalo rumen fermentation.

Synthesis of MCP accounts for $59 \%$ of duodenal absorbable proteins in ruminants [12]. Earlier studies have reported that supplementation of long-chain unsaturated fatty acids (at 3\%) increased bacterial protein while decreasing protozoan protein contents. Moreover, it also enhanced the dehydrogenase activity of rumen microorganisms due to resultant changes in rumen fermentation patterns [13]. The results of the present study were in agreement with these findings as they also observed an increase in MCP contents with the addition of linoleic acid, while the concentration of MCP decreased with the addition of linolenic acid.

\section{Effect of linoleic and linolenic acids on VFA contents}

Volatile fatty acids (VFAs) are the final product of rumen microbial fermentation and serve as intermediate metabolites in the energy harvesting process in ruminants. Acetic acid, propionic acid, and butyric acid account for about $95 \%$ of the total VFAs. The VFAs produced in the rumen had significant impacts on the metabolism of ruminants as they generally provide $70-80 \%$ of the dietary energy required by the animal. Total VFA contents and their composition are essential indicators of the digestive and metabolic functions of the rumen [14]. Acetic acid is an essential volatile fatty acid in the rumen which is 
a precursor for the synthesis of body and milk fat. Previous studies have shown that the ratio of linoleic to linolenic acid in different substrates significantly changed in vitro fermentation kinetics leading to variable productions of acetic and propionic acid by different types of fatty acids 7 . Studies have reported vegetable oils rich in linolenic acid and polyunsaturated fatty acids (PUFA) significantly changed rumen fermentation, increased total VFAs, reduced acetate: butyrate ratio while increasing propionic acid ratio [15]. Moreover, acetate to propionate ratio was significantly decreased by supplementation of $\mathrm{C}-18$ fatty acids under in vitro fermentation. Similar findings were obtained in the present study as acetate to propionate ratio was significantly decreased by both fatty acids. This decrease was more pronounced in the case of linolenic acid because it decreased acetate to propionate ratio from 1.60 to 0.80 ; higher levels (3 to $7 \%$ ) did not show any difference among themselves.

Studies have shown that the degree of unsaturation in long-chain fatty acids plays an essential regulatory role in rumen fermentation and VFA concentrations [13,16]. These findings revealed that supplementation of linoleic and linolenic acid mediates rumen fermentation to reduce the production of acetic acid while increasing propionic acid, which was beneficial for the rumen fermentation process and microbial growth while reducing $\mathrm{H}_{2}$ availability for methanogenesis.

\section{Effects of linoleic and linolenic acids on rumen microbes and methanogenesis}

Long-chain fatty acids especially PUFAs, exhibit toxic effects on rumen microbial populations especially protozoa and cellulolytic bacteria which are generally responsible for fiber digestion and $\mathrm{H}_{2}$ release. This effect is primarily mediated through disruption of the cell membrane of microbes especially those of gram+ bacteria. Although no significant effect on the population of total bacteria was observed in the present study, earlier studies have reported the toxic effects of linolenic acid on the dominant species of cellulolytic bacteria through disruption of cell integrity [17]. The present study revealed highly toxic effects of linolenic acid on protozoa and methanogens when compared to linoleic acid and control groups. It is in agreement with earlier studies that have shown a decrease in protozoa and total methanogens in response to supplementation of unsaturated fatty acids 9 . Highly toxic effects of linoleic acid observed on protozoa were also attributed to an overall decrease in methanogenic bacteria owing to ecto- and endo-symbiosis between these two microbial populations [18].

Interestingly, no significant decrease in total bacteria was observed with linoleic acid up to $3 \%$ but higher levels significantly decreased bacteria. However, linolenic acid significantly reduced total bacteria at all levels of supplementation as reported previously $[16,17]$. This is predominantly attributed to direct toxic effects of linolenic acid on microbes, as a reduction in protozoa and methanogens results in $\mathrm{H}_{2}$ accumulation which subsequently leads to decrease cellulolytic bacteria in the rumen. However, comparison of higher levels (5 to $7 \%$ ) of both fatty acids did not show significant differences in bacterial counts. It may be attributed to the fact that higher levels of omega acids are highly toxic to protozoa which reduces the total protozoa count in the rumen. Decrease in protozoa leads to the escape of bacteria from predation resulting in sustaining of total bacterial counts [19].

Primary gasses produced in rumen are $\mathrm{CO}_{2}$ and $\mathrm{CH}_{4}$, with tiny amounts of $\mathrm{N}_{2}$ and $\mathrm{H}_{2}$. The $\mathrm{CH}_{4}$ accounts for about $28.8 \%$ of total ruminal gas production. The amount of total gas production is also an indirect reflection of rumen microbial activity and the extent of fermentation. In this study, supplementation of linoleic and linolenic acid (above $3 \%$ ) reduced total gas production. Supplementation of linoleic acid at levels over 3 $\%$ also significantly reduced $\mathrm{CH}_{4}$ production. Linoleic acid at a lower level (1\%) was not effective in reducing total gas or $\mathrm{CH}_{4}$ production; however, with higher levels $(3,5$, and $7 \%$ ), it reduced methane up to 25,50 and $57 \%$, respectively when compared to control group. However, linolenic acid was most effective in $\mathrm{CH}_{4}$ inhibition because it significantly reduced $\mathrm{CH}_{4}$ production in a dose-dependent fashion owing to its highly toxic effects on methanogens. But linoleic acid showed no significant decrease in total methanogenic archaea. However, a decrease observed in $\mathrm{CH}_{4}$ production in response to supplementation of linoleic acid was mainly contributed by the reduction in protozoa and methanogenic bacteria.

Linolenic acid showed excellent potential to reduce $\mathrm{CH}_{4}$ at all levels as it decreased $\mathrm{CH}_{4}$ up to $10,63,84$, and $98 \%$ with increasing levels of $1,3,5$ and $7 \%$ of supplementation, respectively when compared to control. The highest level of $\mathrm{CH}_{4}$ reduction in response to supplementation of linolenic acid was mainly attributed to its highly toxic effects on protozoa and methanogenic archaea. Elimination of protozoa from in vitro culture resulted in two-fold effects, firstly by reducing $\mathrm{H}_{2}$ release and secondly by decreasing 
its subsequent reduction into $\mathrm{CH}_{4}$ by methanogenic bacteria and archaea. Similar findings have been observed regarding the decrease in protozoa that was associated with methane reduction in sheep supplemented with 7 $\%$ soy oil hydrolysate [19].

Considering the overall effects of supplementation of fatty acids on in vitro rumen fermentation, microbial populations, and methanogenesis, the most desirable effects on rumen fermentation was observed with $3 \%$ linolenic acid. A higher concentration of propionate was observed as compared to acetate and butyrate contents at this level. Because at this level (3\%), linolenic acid significantly inhibited the growth and predatory activity of protozoa, leading to an increase in total bacteria, which subsequently resulted in the highest MCP and lower $\mathrm{NH}_{3}-\mathrm{N}$ [20]. These findings are in agreement with earlier in vitro studies on goats which also revealed that a $3 \%$ level of linolenic acid was most effective in the manipulation of rumen fermentation kinetics $[9,13]$. Furthermore, findings of the present study revealed that this level was also most appropriate regarding the reduction of $\mathrm{CH}_{4}$ production as a $63 \%$ reduction in methane was observed at this level as compared to the control. The escape of metabolic $\mathrm{H}_{2}$ from reduction by methanogens provides an opportunity for propionate producing bacteria to utilize it to produce more propionate; which was evident from highest propionate concentration observed in the present study. To the best of our knowledge, it is the first report on the effect of linolenic acid on the reduction of methane emanation in the buffalo. It provides extensive evidence that supplementation of linolenic acid enhances energetic efficiency in buffaloes by improving rumen fermentation with directing $\mathrm{CH}_{4}$ energy into propionate production. These findings reveal that linolenic acid is more effective in enhancing rumen fermentation while reducing methane production in high roughage diets when compared to linoleic acid.

\section{CONCLUSION}

The present study has revealed that supplementation with linoleic and linolenic acids decreased $\mathrm{CH}_{4}$ production with more pronounced effects observed at higher levels. The decrease in $\mathrm{CH}_{4}$ was well associated with an increase in propionate concentration in response to treatment with linoleic and linolenic acids. Supplementation with linolenic acid significantly reduced the population of protozoa and methanogens in a dose-dependent fashion. The findings revealed that linolenic acid was more effective with a $3 \%$ level in enhancing rumen fermentation while reducing $\mathrm{CH}_{4}$ production (63 $\%$ ) in high roughage diets when compared to linoleic acid. However, comprehensive in vivo trials are required to provide insights into the practical application of these fatty acids as feed additives to enhance rumen fermentation, production performance while reducing methane emanation.

\section{DECLARATIONS}

\section{Conflict of interest}

No conflict of interest is associated with this work.

\section{Contribution of authors}

Chengjian Yang conceived and designed the study, supervised the data collection and procured funding for the experiment. Mengwei $\mathrm{Li}$ performed the experiment and collected the data. Faizul Hassan analysed the data, and wrote the manuscript and revised it. Lujian Peng managed the laboratory resources and helped in lab work. Hossam Mahrous Ebeid helped in graphical representation of the data and revised the manuscript. Zhenhua Tang, Fang Xie, and Kaiping Peng managed the animals, collected the rumen fluid samples and helped in measurement of gas and $\mathrm{CH}_{4}$ contents at different time intervals. Mengwei Li and Faizul Hassan contributed equally to this work.

\section{Open Access}

This is an Open Access article that uses a funding model which does not charge readers or their institutions for access and distributed under the terms of the Creative Commons Attribution License (http://creativecommons.org/licenses/by/ 4.0) and the Budapest Open Access Initiative (http://www.budapestopenaccessinitiative.org/rea d), which permit unrestricted use, distribution, and reproduction in any medium, provided the original work is properly credited.

\section{REFERENCES}

1. Gerber PJ, Steinfeld H, Henderson B, Mottet A, Opio C, Dijkman J, Falcucci A, Tempio G: Tackling climate change through livestock: a global assessment of emissions and mitigation opportunities. FAO 2013.

2. Grossi G, Goglio G, Vitali A, Williams AG: Livestock and climate change: impact of livestock on climate and mitigation strategies. Animal Frontiers 2019, 9:1-8.

Trop J Pharm Res, September 2021; 20(9): 1808 
3. Haque MN: Dietary manipulation: a sustainable way to mitigate methane emissions from ruminants. Journal of animal science and technology 2018, 60:15.

4. Johnson K, Kincaid R, Westberg H, Gaskins C, Lamb B, Cronrath J: The effect of oilseeds in diets of lactating cows on milk production and methane emissions. Journal of dairy science 2002, 85:1509-1515.

5. Machmüller $A$, Ossowski $D$, Wanner $M$, Kreuzer $M$ : Potential of various fatty feeds to reduce methane release from rumen fermentation in vitro (Rusitec). Animal feed science and technology 1998, 71:117-130.

6. Lins TD, Terry S, Silva R, Pereira LG, Jancewicz LJ, He ML, Wang Y, Mcallister TA, Chaves AV: Effects of the inclusion of Moringa oleifera seed on rumen fermentation and methane production in a beef cattle diet using the rumen simulation technique (Rusitec). animal 2019, 13:283-291.

7. Potu RB, Abughazaleh AA, Hastings $D$, Jones $K$, Ibrahim $S A$ : The effect of lipid supplements on ruminal bacteria in continuous culture fermenters varies with the fatty acid composition. The Journal of Microbiology 2011, 49:216-223.

8. Liu S, Bu D, Wang J, Liu L: Effect of incremental levels of fish oil supplementation on specific bacterial populations in bovine ruminal fluid. Journal of animal physiology and animal nutrition 2012, 96:9-16.

9. Jian $G$, Jing $Y$, Wang $M$, Shi L, Liu S: The effects of the unsaturated degree of long-chain fatty acids on the rumen microbial protein content and the activities of transaminases and dehydrogenase in vitro. Journal of Integrative Agriculture 2016, 15:424-431.

10. $Y u Z$, Morrison M: Improved extraction of PCR-quality community DNA from digesta and fecal samples. Biotechniques 2004, 36:808-812.

11. Ørskov E: Recent advances in understanding of microbial transformation in ruminants. Livestock production science 1994, 39:53-60.

12. Clark J, Klusmeyer T, Cameron M: Microbial protein synthesis and flows of nitrogen fractions to the duodenum of dairy cows. Journal of dairy science 1992, 75:2304-2323.

13. Jian $G$, Wang $M$, Jing $Y$, Sun $X, W u T$, Shi L: Impacts of the unsaturation degree of long-chain fatty acids on the volatile fatty acid profiles of rumen microbial fermentation in goats in vitro. Journal of integrative agriculture 2016, 15:2827-2833.

14. Bannink A, France J, Lopez S, Gerrits WJ, Kebreab E, Tamminga S, Dijkstra J: Modelling the implications of feeding strategy on rumen fermentation and functioning of the rumen wall. Animal Feed Science and Technology 2008, 143:3-26.

15. Zhang C, Guo Y, Yuan Z, Wu YM, Wang JK, Liu JX, Zhu WY: Effect of octadeca carbon fatty acids on microbial fermentation, methanogenesis and microbial flora in vitro. Animal Feed Science and Technology 2008, 146:259-269.

16. Martin C, Rouel J, Jouany J, Doreau M, Chilliard Y: Methane output and diet digestibility in response to feeding dairy cows crude linseed, extruded linseed, or linseed oil. Journal of Animal Science 2008, 86:26422650.

17. Maia MR, Chaudhary LC, Figueres L, Wallace $R J$ : Metabolism of polyunsaturated fatty acids and their toxicity to the microflora of the rumen. Antonie Van Leeuwenhoek 2007, 91:303-314.

18. Finlay BJ, Esteban G, Clarke KJ, Williams AG, Embley TM, Hirt RP: Some rumen ciliates have endosymbiotic methanogens. FEMS Microbiology Letters 1994, 117:157-161.

19. Broudiscou L, Van Nevel C, Demeyer D. Incorporation of soya oil hydrolysate in the diet of defaunated or refaunated sheep: effect on rumen fermentation in vitro. Archives of Animal Nutrition 1990, 40:329-337.

20. Ebeid HM, Mengwei L, Kholif AE, Hassan F, Lijuan P, Xin $L$, Chengjian Y. Moringa oleifera oil modulates rumen microflora to mediate in vitro fermentation kinetics and methanogenesis in total mix rations. Current microbiology, 2020, 1-12. 